\title{
ERRATUM
}

K. D. Jermstad • L. A. Sheppard • B. B. Kinloch •

A. Delfino-Mix • E. S. Ersoz • K. V. Krutovsky •

D. B. Neale

\section{Isolation of a full-length CC-NBS-LRR resistance gene analog candidate from sugar pine showing low nucleotide diversity}

Published online: 16 March 2006

(C) Springer-Verlag 2006

\section{Tree Genetics and Genomes (2006) 6:76-85}

The HTML version of this article was originally published with an incorrect list of authors. Please see the correct list above.

The HTML files have now been corrected.

The online version of the original article can be found at http://dx.doi.org/10.1007/s11295-005-0029-6

K. D. Jermstad · L. A. Sheppard · B. B. Kinloch ·

A. Delfino-Mix · K. V. Krutovsky · D. B. Neale $(\triangle)$

USDA-Forest Service, Pacific Southwest Research Station, Institute of Forest Genetics,

2480 Carson Road,

Placerville, CA 95667, USA

e-mail: dbneale@ucdavis.cdu

E. S. Ersoz · D. B. Neale

Department of Plant Sciences, University of California,

1 Shields Avenue,

Davis, CA 95616, USA

Present address:

L. A. Sheppard

Ingenuity Systems,

1565 Charleston Road,

Mountain View, CA 94043, USA 